\title{
Environmental Challenges Associated with the Development of Socio-Economic Activities in East African Countries Comparative Study with China
}

\author{
Sahim Abdalla Juma1, Mngereza Mzee Miraji² \\ ${ }^{1}$ School of Public Affairs, University of Science and Technology of China, Hefei, China \\ ${ }^{2}$ Peking University, College of Engineering, Beijing, China \\ Email: sahim@mail.ustc.edu.cn, mngereza@gmail.com
}

How to cite this paper: Juma, S.A. and Miraji, M.M. (2018) Environmental Challenges Associated with the Development of Socio-Economic Activities in East African Countries Comparative Study with China. Journal of Environmental Protection, 9, 1129-1141.

https://doi.org/10.4236/jep.2018.910070

Received: July 17, 2018

Accepted: September 18, 2018

Published: September 21, 2018

Copyright $\odot 2018$ by author and Scientific Research Publishing Inc. This work is licensed under the Creative Commons Attribution International License (CC BY 4.0).

http://creativecommons.org/licenses/by/4.0/

(c) (i) Open Access

\begin{abstract}
This study is presenting a Policy analysis of the related environmental challenges associated with the development of socio-economic activities between China and East African countries. The author thinks that Socio-economic issues and economic development have a direct impact on the environment hence need to be studied for the purpose of policy formulation. This study analysed the policies on environmental issues in China and its five-year economic plan. Furthermore, this study examined what the Chinese government has done about socio-economic activities and what lessons are available for East African countries. Finally, this paper proposed possible solutions for East African countries on environmental challenges associated with the development of socio-economic activities with the potential for combining economic and ecological interests in East Africa. This study can help (potential) Government officers, policymakers, and regulators to assess environmental risks with lessons from China.
\end{abstract}

\section{Keywords}

Public Policy, Resource Management, China, East Africa, Environmental Planning, Economic Development, Biodiversity

\section{Introduction}

More than $70 \%$ of the African population lives in rural areas, depending directly on the natural environment and land for their livelihoods and well-being [1]. 
Therefore, improved use of environmental goods and services could influence socio-economic indicators and ensure sustained economic growth [2].

The East African economy is at developing stage, a time when the new industries are introduced in the economy, new manufacturing plants and processing factories are constructed, and many rural dwellers are moving to big cities looking for new job and more socio-economic benefits.

Human socio-economic issues affect environmental change at the local, national, regional and global levels. Drivers of environmental change vary in nature and scope but can generally be classified as economic and social, science and technology, demographics, and conflict and governance. Although each driver is discussed individually, different drivers show relationships and sometimes act in synergy to maximise negative impacts and produce positive change [2].

While East Africa is developing, it is the right time for policymakers to establish sustainable policies that will protect the environment and support the future social needs that include safe water, good air quality and food security to mention a few.

China despite having the largest population on the earth, has managed to establish policies that support the social need while also protecting the country eco-system.

\section{Opportunities Framework for Analysis}

The author adapted Figure 1 from the Driver's Pressures State Impact Response (DPSIR [3]) conceptual framework that is focusing the assessment on the available resource base, which provides opportunities for sustainable development and enhanced human well-being. The environmental resources, including goods and services, are taken as the asset base available to help reduce human vulnerability to environmental change.

The Figure 1 shows that Drivers like material, human and social capital have a direct impact on human society and its environment as seen on Impact (I). For example, the population driver can have a direct impact on basic needs, security, health and good social relation. These can results in human development or more poverty if they are not well managed.

Because of Pressure (P), Human interventions are highly needed on the issues like land use, natural resources extractions, external input like fertilisers and emission need to be monitored and controlled.

Responses (R) suggests that formal and informal initiatives are needed to protect the environment and its ecosystem through monitoring human movement and development by using strict laws, regulations and policies.

In order to protect the environment and make it more sustainable, as seen in State and Trends (S) in the DPSIRframework, East African states need to have specific policies on land, water, biodiversity, climate change, pollution, soil degradation, land and minerals. 


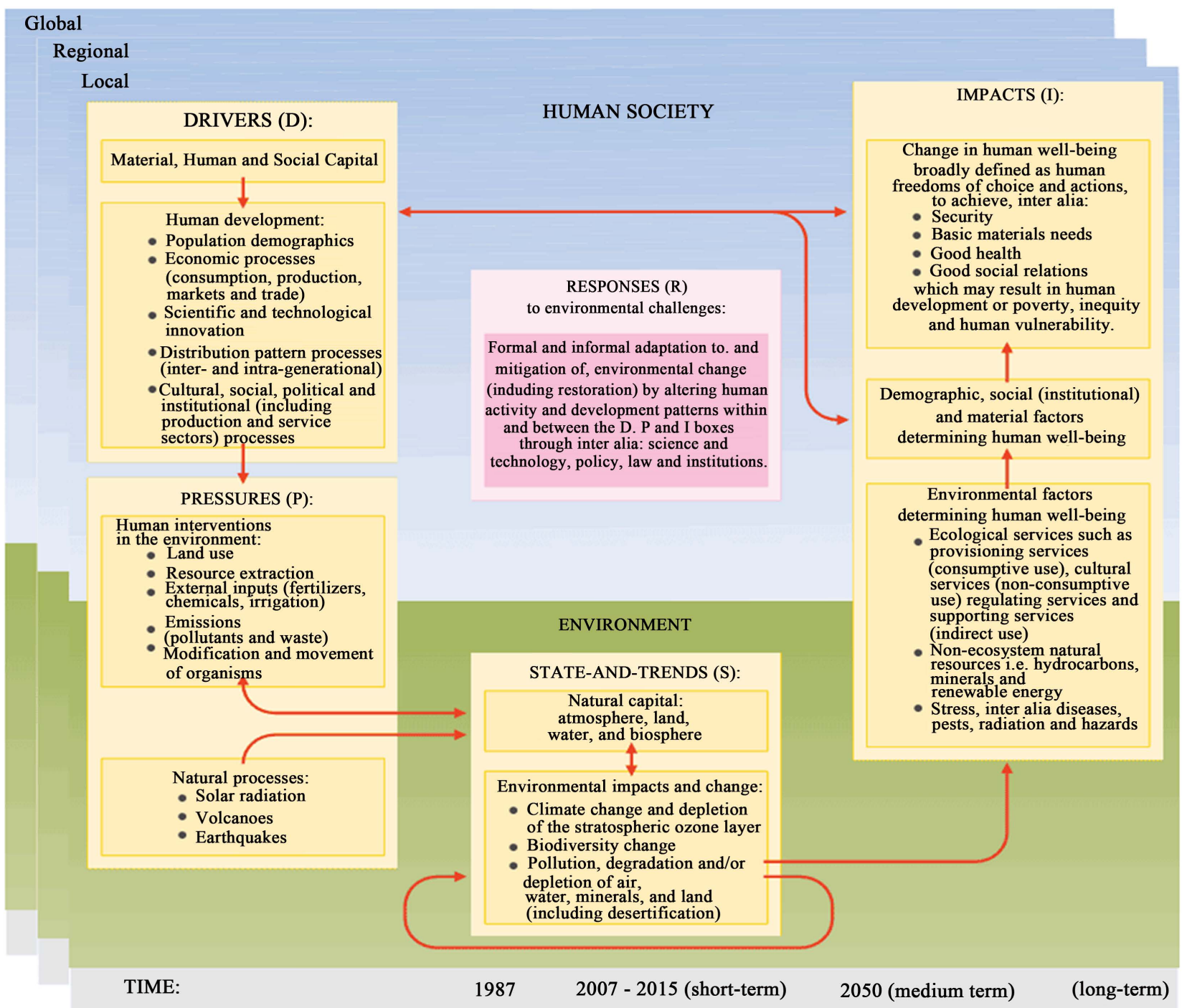

Figure 1. Opportunities framework for analysis. Source: Driver's pressures state impact Response (DPSIR) [3].

\section{China Economic Overview}

According to World Bank, China has shifted from a centrally planned to a market-based economy and has experienced rapid economic and social progress since the introduction of market transformations in 1978. GDP increased to an average of approximately $7 \%$ year to raise an additional 750 million individuals out of poverty. Overall, the Millennium Development Goals have been reached or are within reach of some projects to be completed in environment goals (notably air pollution reduction).

With a populace of 1.3 billion, China currently has the second largest economy and is gradually playing a vital role in the world economy.

Fast economic power growth has also led to many challenges, including high inequality, rapid urbanisation (see Table 1), challenges to eco-friendly sustainability and exterior imbalances. China is also experiencing demographic burdens due to an ageing populace and internal labour movement. 
Table 1. China-urban migration.

\begin{tabular}{ccc}
\hline Date & Value & Change, \% \\
\hline 2016 & $11,391.62$ & $1.88 \%$ \\
2015 & $11,181.56$ & $5.91 \%$ \\
2014 & $10,557.64$ & $9.57 \%$ \\
2013 & 9635.21 & $12.43 \%$ \\
2012 & 8570.28 & $13.93 \%$ \\
2011 & 7522.16 & $24.00 \%$ \\
2010 & 6066.21 & $18.43 \%$ \\
2009 & 5121.99 & $11.23 \%$ \\
2008 & 4604.73 & $28.92 \%$ \\
2007 & 3571.65 & $28.74 \%$ \\
2006 & 2774.27 & $20.16 \%$ \\
2005 & 2308.82 & \\
\hline
\end{tabular}

Source: China department of statistics.

Environmental policies in China need significant adjustments to promote the country's sustainable growth. Experience shows that transitioning from middle-income to high-income status can be harder than that from low-income to middle-income status.

China's 12th Five-Year Plan (2011-2015) persuasively addresses these issues and highlights the progress of services and actions to address environmental and social disparities, set goals to decrease pollution, upsurge energy efficiency, expand access to education and healthcare and increase social protection. The annual growth target of $7 \%$ signals the intent to emphasise the quality of life rather than the pace of development, see Graph 1.

China's Environmental Encounter: Political, Social and Economic Consequesnces

The Council on Foreign Relations has reported that China's remarkable economic development, which averages more than $8 \% /$ year over the previous two decades, has significantly increased the standard of living for hundreds of millions of Chinese residents. Similarly, this economic growth has considerably impacted China's atmosphere and environmental protection.

In China, the demand for natural resources of all types, including water, land and energy, has dramatically increased. Exhaustion of forest resources has triggered various unexpected secondary effects, such as massive desertification, regular flooding and species loss. The levels of water and air pollution have also steeply increased due to poorly controlled manufacturing and daily household pollutant emissions and wastes.

Furthermore, the growth and environmental practices in China have rendered the nation one of the world's top contributors to regional and worldwide 


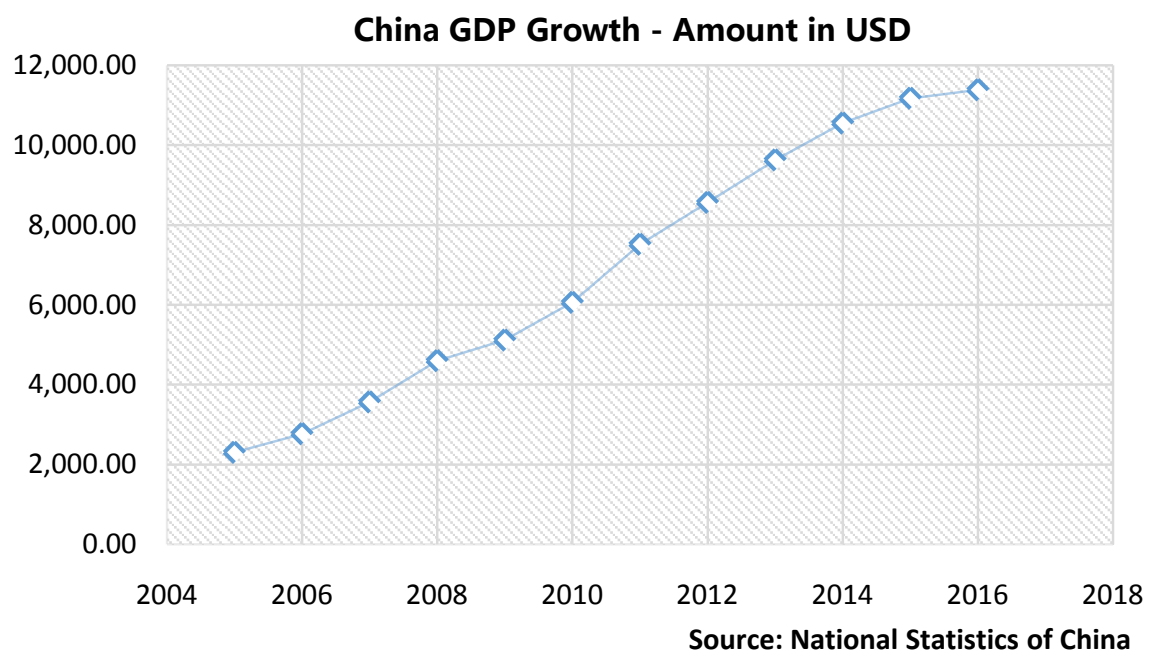

Graph 1. China GDP growth.

environmental problems, including acid rain, ozone depletion, global climate change and biodiversity loss.

\section{Social and Economic Costs of Environmental Pollution in China}

China tolerates several indirect and growing costs from its resource burdens, including migration, public health, social unrest and declining economic efficiency.

\subsection{Migration}

In the 1990s, 20 - 30 million farmers were displaced by environmental degradation, and at least 30 - 40 million farmers may need to be relocated by 2025 . These migrants place substantial tension in cities that even now seek to manage migrant populations of more than $20 \%$ of the populace in numerous major Chinese cities, such as Beijing. Urban population in China big cities are growing very fast (see Table 2).

Urban population refers to people living in urban areas as defined by national statistical offices. It is calculated using World Bank population estimates and urban ratios from the United Nations World Urbanization Prospects.

\subsection{Public Health}

In 2000, the Ministry of Agriculture stated that approximately $20 \%$ of agricultural and poultry goods in leading industrial and mining districts and areas flooded with contaminated water contained high levels of contamination.

\subsection{Economic Productivity}

Environmental economists universally agree that the overall cost to the Chinese government for environmental degradation and resource scarcity is $8 \%$ to $12 \%$ of the GDP every year. The highest price is for health and production losses 
Table 2. China-Urban population.

\begin{tabular}{lcc}
\hline Date & Value & Change, \% \\
\hline 2015 & 55.6 & $2.21 \%$ \\
2014 & 54.4 & $2.34 \%$ \\
2013 & 53.2 & $2.46 \%$ \\
2012 & 51.9 & $2.60 \%$ \\
2011 & 50.6 & $2.74 \%$ \\
2010 & 49.2 & $2.81 \%$ \\
2009 & 47.9 & $2.88 \%$ \\
2008 & 46.5 & $2.96 \%$ \\
2007 & 45.2 & $3.03 \%$ \\
2006 & 43.9 & $3.17 \%$ \\
2005 & 42.5 & $3.35 \%$ \\
2004 & 41.1 & \\
\hline
\end{tabular}

Source: China department of statistics.

related to city air pollution, which the World Bank approximates to be more than USD 20 billion. Water scarcity in Chinese cities costs approximately USD 14 billion in lost manufacturing productivity (when plants are required to shutdown).

\section{Chinese Policies for Minimising the Environmental Challenges Related to Socio-Economic Activities}

\subsection{Combination of Environmental Safety and Economic Development}

First, policy supervision is exercised by the central state agencies. China's National Environmental Protection Administration, National Development and Planning Commission, National Economic and Trade Commission and Environmental Protection and Natural Resources Committee of the State People's Congress, amongst others, play significant roles in assimilating environmental protection and economic growth and convey different interests and priorities to be allowed and implemented all over China.

\subsection{Decentralisation of Environmental Accountability to the Local Government}

Another cognisant policy of the Chinese government since 1989 has been to decentralise authority for environmental protection to the local government. This system is fruitful with one challenge that the wealthy local government like Shanghai has accomplished well.

\subsection{Collaboration with the International Community}

The third component of China's strategy to ensure the progress of its overall en- 
vironment is to tap into the know-how and resources of the global community. China is the primary receiver of environmental assistance from the World Bank, the Asian Development Bank, the Global Environmental Facility and Japan.

\subsection{Developing Public Green Politics}

China has opened access to the participation of non-governmental organisations, environmental parties, the general public and the media in environmental protection policy implementation.

\subsection{Improving the Legal Structure for Environmental Protection}

Over the past decade, the Chinese administration has formulated large spaces on the jurisdictional side, passing upwards of 25 environmental protection decrees and 100 secretarial regulations in addition to hundreds of environmental canons.

\section{Literature Review}

Socio-economic Activities: Socio-economic activities refer to the studies of how business affects and is formed by social processes. It examines how societies progress, stagnate or regress because of their local, regional or global economy [3].

Socio-economic issues or indicators cause the influence of socio-economic activities. Socio-economic problems involve demographic, conflict and governance and science and technology [4].

Agriculture is considered the main economic activities, particularly in Sub-Saharan Africa, which account for approximately $20 \%$ to $30 \%$ of the GDP, represent $55 \%$ of their national exports, account for $38 \%$ of their total urban population and can be credited to $60 \%$ of the region's GDP [5].

The significant environmental challenges faced by African countries are related to climate change, biodiversity, pollution and waste, unsustainable management of water resources and depletion of marine and coastal areas. In Africa, approximately $27 \%$ of the global land is degraded, with 500 million ha moderately to severely degraded [5].

The public in Africa is at the centre of sustainable growth in rural and urban parts. Although still typically rural, the region has been undergoing a significant transformation of its population structure and distribution, with favourable and adverse consequences for the environment and growth. The challenge is not to arrest growth but to use the available resources productively and efficiently, ensuring improved and more reasonable returns for people while decreasing environmental pressure.

The rapid population growth is accompanied by rapid development pressures, with the high demand for housing and infrastructure having already affected the environment in most African cities. This impact on environmental hazards increases demands on fragile economies and depletes limited resources [5]. The increase in population densities, food shortages and insecurity and malnutrition 
with associated diseases has resulted in acute forms of poverty in Africa.

Poverty and health are also critical social dimensions. Policy and institutions are the responses to mitigate such change, drive environmental change and have a direct impact on human vulnerability. Although each driver is discussed individually, different drivers show relationships and sometimes act in synergy to maximise negative impacts and produce positive change [4].

Energy dynamics, socio-economic development and environmental sustainability, are linked to the triple challenges facing African countries because the majority of energy forms have been constructed in the area of intense competition for arable lands for food crops and feedstock cultivation. As a result, the socio-economic factors of most countries in Sub-Saharan Africa are influenced [6].

From this point of view, the energy sector, which drives almost every sub-sector of the broader socio-economic activity, should consider the environmental effects of extraction and use it against the corresponding impacts of climate variability and change in a cycle of sustainability [6].

\subsection{Socio-Economic Indicators}

An indicator is something which points to something other than itself [7]. Socio-economic indicators refer to the health scenario in a country. It can provide data on education, gender, housing, amenities, employment, poverty and other economic indicators. These indicators can be used in a country or state to identify the link between socio-economic indicators and achieving their goals [8].

Socio-economic indicators are used to measure social and economic development within a particular populace. Statistics are obtained from the census, national databases or surveys in an area and is used to evaluate community features, such as employment rate, population rate, literacy level, life expectancy, poverty and per capita income.

\subsubsection{Population/Demographic}

Population change is the principal driver of land cover change. Its influence is through opening new land for farming, settlement, infrastructural development, logging and mining [4]. Rural areas have been undergoing significant changes in population composition and distribution, and these changes entail positive and negative effects on the environment and growth. Thus, population increase and its fundamental changes are addressed to decrease environmental degradation.

The population increases annually, but natural resources are lacking to bear this population, to develop the quality of lives and to eradicate poverty. As a consequence, sustainable development remains challenging [4].

\subsubsection{Per Capita Income}

Per capita income is an indicator which most directly measures the material resource components. Income can influence a wide range of physical circumstances with direct implications for human well-being. Income also has a cumulative effect on the life course and is the socio-economic indicator which can 
change on a short-term basis [9].

Income growth influences the environmental performance of countries; in specific, this performance increases with income but decreases with the further increase of the same [10].

Individual material characteristics are captured by personal income, such that household income may be a useful indicator to apply to all household members, assuming an even distribution of revenue according to household needs, which may or may not be true [9].

\subsubsection{Employment}

Employment can be represented as a reflection of a person's status in society related to their income, social standing and intellect which characterise the working relationship between employer and employee or, less frequently, describe people as exploiters or exploited in class relations [9]. Employment can be used to measure the proportion of the labour force which is unemployed and which is available for work.

\subsubsection{Literacy}

Education is crucial for effective environmental management; it significantly affects the economy and the livelihood choices of people [4]. The absence of improved access to formal education, in consideration of the reduction of illiteracy rates, environment-friendly-related issues and practical education, as well as the continuation of few opportunities available to most people, could negatively impact the environment.

\subsubsection{Life Expectancy}

Life expectancy is the average period a person may expect to live. Environmental conditions affect life expectancy and longevity. Life expectancy and environmental dynamics can be jointly determined [11].

Some countries might be trapped in a low life expectancy or weak environment quality. The outcome is consistent with the fact that it relates life expectancy and environmental performance measures. Thus, a person expected to have a long life should be willing to capitalise on environmental quality [11].

\subsubsection{Mortality}

Mortality can be defined as the state of being subject to death or death on a large scale. Environmental quality is a predominant factor which affects health and morbidity; for instance, water and air pollution, soil degradation and natural resource depletion can increase human mortality [12].

\section{Discussion and Possible Solutions}

The author concludes that East African countries must formulate policies to protect the environment as a result of socioeconomic activities in their specific countries. Also, the East African countries must have a good strategy for environmental protection as a result of ongoing economic development in East 
Africa.

The author has highlighted the following lessons from China on environmental challenges connected with the development of socio-economic activities that can be applied to East African countries.

What the author emphasises to East African countries policymakers is to localise these lessons and policies from China according to their local needs. Some policies need to be amended and improved to match with the East African situation.

\subsection{Demographic Change}

Even though the East African region is mostly rural, the area has been undergoing a significant shift in population formation and distribution, and this shift entails constructive and adverse effects on the environment and growth.

The challenge is not to arrest growth but to use the available resources productively and efficiently, guaranteeing improved and more justifiable yields to people while decreasing the burden on the environment. China Population is enormous compared to East African countries, but even though, the urbanisation rates are still huge in most of the big cities in East Africa including Nairobi, Kampala and Daresalaam to mention a few.

From the Chinese demographic change viewpoint, East African countries can implement Chinese smart cities (Satelite cities) and migration policies and approaches including higher taxation rate in all major East African cities. China has experience a lot of success in the apportionment of land for agriculture, land ownership registration (Hukou), construction of new smart cities like in Beijing and registration, management and support for migrant workers.

\subsection{Agriculture}

Agriculture is considered vulnerable to environmental hazards and the impacts of climate change. Nevertheless, sustainability and productivity should be increased to enhance the livelihood of the population considerably. Meanwhile, East African countries can learn and implement some of the agricultural methods and techniques adopted by the Chinese government. The East African countries can use modern agriculture technologies like drip irrigation and environmental friendly fertilisation to boost the agricultural output while also protecting the environment.

\subsection{Bio-Trade}

Trade in biodiversity-based businesses or bio-trade refers to the collection, production, transformation and commercialisation of goods and services derived from native biodiversity under the criteria of environmental, social and economic sustainability [13].

East Africa's ironic biodiversity and its accumulated knowledge give rise to new products for commercialisation and export. These products could include livestock breeds, wildlife, homegrown crops and vegetables, timber and non-timber 
forest products, native fisheries and aquatic resources and domestic natural products. Associated to its potential, bio-trade is underdeveloped in most countries in the East African region.

If bio-business is to flourish in East Africa sustainably, then ensuring that ecosystems are used is essential, such that exploitation can occur in the long run, which will signify another opportunity for preserving national natural resources. Domestic products, building capacity for the supply chain and building markets should also be improved.

\subsection{Organic Agriculture}

This study defines organic agriculture as a production system which sustains the health of soils, ecosystems and people and relies on ecological processes, biodiversity and cycles adapted to local conditions rather than the use of inputs with adverse effects. Organic agriculture combines tradition, innovation and science to benefit the shared environment and promotes healthy relationships and a good quality of life for all involved [14].

Organic agriculture often facilitates the exploration of alternative farming methods which preserve the environment through the use of organic fertilisers instead of agrochemicals or organic farming methods instead of harmful production methods for different commodities, such as cotton, pineapple or palm oil.

Organic agriculture has not been fully implemented in East African countries, and the production volumes are small. Many farmers in East African countries use organic agriculture to grow products for local consumptions only. Farmers in China engage in organic agriculture, which has resulted in food sufficiency with a reserve for export. This technique indicates that by investing in natural farming methods, East African countries can yield large amounts of agricultural products to meet the needs of their citizens, improve food security and export the remaining products, including cash crops. The agricultural scientists should research and develop organic agricultural methods that match with the weather, soil and available resources in East Africa.

\subsection{Energy}

Access to energy is one of the most significant challenges in all East African countries and, consequently, bears a high potential for economic development in this region. For example, the World Bank Little Data Book on Climate Change reported that only $13.9 \%$ of the total population of Tanzania has access to electricity. A series of programs which promote renewable energies (e.g. biogas, solar and natural gas) is underway in East African countries. China, which is heavily dependent on coal for its electricity, is now shifting towards new energy sources, such as nuclear power plants and wind and solar electricity sources.

Access to energy increases the quality of life in rural communities while creating employment and providing opportunities for the development of Green 
and Inclusive Business Models. Moreover, the installation and maintenance of renewable energy systems in remote areas directly create jobs.

East African Policymakers should consider the new energy sources including renewable energy investments that match with their local need and that have a higher cost to benefits advantages. Even though these new energy sources are very expensive for many East African countries to afford, but then there is various investment model that can be applied to support the funding of these mega energy projects that includes a soft loan from China and Public Private Partnership model (PPP).

Concerning different initiatives and examples, carbon markets and emissions-reducing initiatives play an increasing role in East Africa in the years to come. These initiatives and examples are significant drivers for greening the economy because of their considerable potential for fostering energy efficiency, renewable energy solutions and reforestation while providing employment.

\subsection{Forestry}

Another environmental challenge in East Africa is deforestation. In East Africa, farmland increased by $50 \%$ since 1980 [15]. Meanwhile, forests are a significant source of fuelwood in East Africa. Rapid deforestation severely affects desertification and climate change in East Africa [16].

Similar to China, East African countries can implement active measures towards protecting forestry. Reliable institutions should establish new policies with the goal of protecting forestry. High tax should also be levied to discourage investors who are using forestry products.

Some East African countries like Tanzania, has come up with policies for banning forest harvesting for wood exportation for a period of time. This policy can help the forestry products to have needed time to mature and monitored during the harvesting period with strict procedures to be followed.

The author believes that the methods mentioned in this study can minimise the challenge which is directly associated with socio-economic activities in East Africa. The recently proposed policies in China, including its new 13th Economic Plan, help minimise the challenges above and thus can be adopted by East African countries.

\section{Conflicts of Interest}

The author declares no conflict of interest.

\section{The Data Availability Statement}

The data used to support the findings of this study are available from the corresponding author upon request.

\section{References}

[1] IFAD (2001) Rural Poverty Report 2001: The Challenge of Ending Rural Poverty, 
International Fund for Agricultural Development. Oxford University Press, New York.

[2] Kulindwa, K., Kameri-Mbote, P., Mohamed-Katerere, J., Chenje, M. and Sebukeera, C. (2012) Our Environment, Our Wealth, Africa Environment Outlook 2. UNEP, Nairobi.

[3] UNEP (2006) Africa Environment Outlook-2: Our Environment, Our Wealth. United Nations Environment Programme, Nairobi, 31.

[4] Wikipedia (2015) Definition of Socio Economic Activities.

[5] UNEP (2013) Environmental Change and Socioeconomic Factors in Africa. Annual Report Job Number: DCP/1792/NA, UNEP, Nairobi.

[6] Ndoye, F. and Sindayigaya, L. (2009) Africa's Environmental Challenges. African Hub Project Coordinators, African Union Commission, Addis Ababa.

[7] United Nations: Economic and Social Council, United Nations: Economic Commission for Africa (1984) Definition, Selection and Use of Socio-Economic Indicators. ECA Expert Consultation on a System of Socio-Economic Indicators for African Planners, Addis Ababa, 23-27 January 1984.

http://repository.uneca.org/handle/10855/14513?locale-attribute=en\&

[8] United Nations Economic and Social Council (1984) Economic Commission for Africa. Expert Consultation on a System of Socio Economic Indicators for African Planners, Addis Ababa, Ethiopia.

http://repository.uneca.org/bitstream/handle/10855/14513/Bib-56066.pdf?sequence $=1$

[9] Galobardes, B., Shaw, M., Lawlor, D.A., Lynch, J.W. and Smith G.D. (2006) Indicators of Socioeconomic Position. Journal of Epidemiology and Community Health, 60, 7-12.

[10] Mukherjee, S. and Chakraborty, D. (2010) Is There Any Relationship between Environment, Human Development, Political and Governance Regimes? Evidence from a Cross-Country Analysis, National Institute of Public Finance and Policy (NIPFP), Indian Institute of Foreign Trade (IIFT), New Delhi.

[11] Mariani, F., Prez-Barahona, A. and Raffin, N. (2009) Life Expectancy and the Environment. IZA Discussion Paper No. 4564. https://ssrn.com/abstract=1506316

[12] Franz, J. and Fitzroy, F. (2006) Child Mortality, Poverty, and the Environment in Developing Countries. University of St. Andrews, St. Andrews, Scotland.

[13] United Nations Conference on Trade and Development (1996) Defitnition of biotrade. Geneva.

http://unctad.org/en/Pages/DITC/Trade-and-Environment/BioTrade.aspx

[14] International Federation of Organic Agriculture Movements IFOAM (2005) Organic Agriculture. Vigona.

https://www.ifoam.bio/en/organic-landmarks/definition-organic-agriculture

[15] Gibbs, H.K., Ruesch, A.S., Achard, F., Clayton, M.K., Holmgren, P., Ramankutty, N. and Foley, J.A. (2010) Tropical Forests Were the Primary Sources of New Agricultural Land in the 1980s and 1990s. PNAS, 107, 16732-16737. https://doi.org/10.1073/pnas.0910275107

[16] FAO (2001) Global Forest Resources Assessment 2000. Main Report. FAO Forestry Paper. Food and Agriculture Organization of the United Nations, Rome. 